\title{
Distribution of genomic regions differentiating oak species assessed by QTL detection
}

\author{
C Saintagne, C Bodénès, T Barreneche, D Pot, C Plomion and A Kremer \\ INRA UMR Biodiversité Gènes et Ecosystèmes, 69, Route d'Arcachon, 33612 Cestas Cedex, France
}

\begin{abstract}
Pedunculate oak and sessile oak are two sympatric interfertile species that exhibit leaf morphological differences. We aimed to detect quantitative trait loci (QTLs) of these traits in order to locate genomic regions involved in species differentiation. A total of 15 leaf morphological traits were assessed in a mixed forest stand composed of Quercus petraea and $Q$. robur and in a full-sib pedigree of $Q$. robur. The progeny of the full-sib family were vegetatively propagated in two successive experiments comprising 174 and 216 sibs, and assessments were made on two leaves collected on each of the 1080 and 1530 cuttings corresponding to the two experiments. Traits that exhibited strong species differences in the mixed stand tended also to have higher repeatability values in the mapping population, thus indicating higher genetic control. A genetic map was
\end{abstract}

constructed for QTL detection. Composite interval mapping with the one QTL model was used for QTL detection. From one to three QTLs were detected for 13 traits. In-depth analysis of the QTLs, controlling the five morphological traits that exhibited the highest interspecific differences in the mixed stand, indicated that they were distributed on six linkage groups, with two clusters comprising QTLs of at least two discriminant traits. These results were reinforced when error 1 for QTL detection was set at 5\% at the chromosome level, as up to nine clusters could be identified. In conclusion, traits involved in interspecific differentiation of oaks are under polygenic control and widespread in clusters across the genome.

Heredity (2004) 92, 20-30, advance online publication, 24 September 2003; doi:10.1038/sj.hdy.6800358

Keywords: QTL; leaf morphology; repeatability; genetic map; $Q$. robur

\section{Introduction}

Pedunculate oak (Quercus robur L.) and Sessile oak ( $Q$. petraea (Matt.) Liebl.) are closely related species with wide sympatric distributions in Europe, although their taxonomic distinctiveness is not clearly defined and has raised conflicting opinions between botanists. Since sessile and pedunculate oak are interfertile in natural conditions (Rushton, 1977), the biological species concept (Mayr, 1963) has been challenged by some authors (Kleinschmit and Kleinschmit, 2000). Even if the two species are sympatric, they occupy different ecological niches within the same stands. Indeed, Q. robur preferentially grows in rich, wetter, and more alkaline habitats, whereas Q. petraea occurs on drier and more acidic soils (Becker and Levy, 1990). Nevertheless, in spite of their ecological differences, the two species coexist in mixed stands and intermediate forms appear under these circumstances (Olsson, 1975; Rushton, 1979; Dupouey, 1983; Bacilieri et al, 1996).

Interspecific variation in mixed oak stands has raised a general interest in Europe since decades among scientists and foresters. The two species exhibit extremely low genetic differentiation, because of their interfertilty and their sympatry. Species differentiation has been tested using various genetic markers, for example, isozymes

Correspondence: A Kremer, INRA UMR Biodiversité Gènes et Ecosystèmes, 69, Route d'Arcachon, 33612 Cestas Cedex, France.

E-mail: antoine.kremer@pierroton.inra.fr

Received: 17 July 2002; accepted: 21 July 2003
(Zanetto et al, 1994; Gömöry, 2000), ribosomal DNA (Petit and Kremer, 1993; Muir et al, 2001), chloroplast DNA (Petit and Kremer, 1993), proteins (Barreneche et al, 1996), and anonymous DNA fragments (Moreau et al, 1994; Bodénès et al, 1997; Cervera et al, 2000; Zoldos et al, 2001; Mariette et al, 2002). These investigations showed the absence of species-specific markers, and that the two species displayed only allele frequency differences. These results differed markedly from phenotypic observations made in mixed stands when the two species coexist, where they show clear ecological preferences and differences in leaf morphological characters. Earlier regional investigations of leaf morphological variation indicated that the two species exhibit quantitative differences when multivariate methods are used (Aas, 1993; Dupouey and Badeau, 1993). A recent study, using the same techniques, over a wider sample of populations confirmed these observations (Kremer et al, 2002) that leaf morphological traits show continuous but bimodal distribution in mixed stands. The discrepancy between genetic and phenotypic differentiation is well illustrated by the genetic survey of Bodénès et al (1997) where only $2 \%$ of the 2800 random amplified polymorphic DNA (RAPD) fragments exhibited significant frequency differences between the two species. These results suggested that genomic regions involved in species differentiation are rare and explain why earlier molecular investigations, using a low number of loci, proved to be inefficient.

In this contribution, we attempt to investigate the distribution of these informative (species-discriminant) genomic regions within the oak genome. The strategy 
adopted is a downstream approach from the informative and discriminant phenotypic traits to their underlying loci. As quantitative differences in phenotypes between individuals are due to the segregation of alleles at multiple quantitative trait loci (QTLs), we intend to map the QTLs that control species-discriminant leaf morphological traits. With the recent and widespread availability of polymorphic molecular markers, QTL mapping has been used to locate the genomic regions involved in interspecific differentiation in various species, for example Drosophila (Zeng et al, 2000), tomato (Grandillo and Tanksley, 1996), monkeyflower (Bradshaw et al, 1998), rice (Brondani et al, 2002), maize (Westerbergh and Doebley, 2002), millet (Poncet et al, 2002), and sunflowers (Kim and Rieseberg, 1999). In the present study, we aimed to locate QTLs of 15 leaf morphological characters that are traditionally used for oak species identification. The QTL detection was performed in a cloned full-sib family of $Q$. robur comprising 278 progeny, while interspecific variation in morphological characters was first estimated on phenotypic values recorded in a natural mixed stand.

\section{Material and methods}

\section{Natural population}

Leaf morphological traits were assessed in a mixed stand of $Q$. petraea and $Q$. robur located in the northwest of France (Bacilieri et al, 1995; Kremer et al, 2002). The study area is square $(250 \mathrm{~m} \times 250 \mathrm{~m})$ and comprises 426 adult trees (older than 100 years), approximately evenly distributed between the two species (199 Q. petraea, 215 $Q$. robur, and 12 so-called intermediate). The data of the intermediate trees were not used. The sampling was exhaustive and five leaves were sampled within the upper crown of each tree. The morphological data, previously reported (Bacilieri et al, 1995; Kremer et al, 2002), will be used here only for the estimation of the variance components of the traits.

\section{Mapping population}

An intraspecific hybrid family of $Q$. robur was obtained by crossing two adult trees. The female parent (accession 3P) was located on the Forestry Research Station of Pierroton (latitude $44.44 \mathrm{~N}$, longitude $0.46 \mathrm{~W}$ ), and the male parent (accession A4) originated from Arcachon (latitude $44.40 \mathrm{~N}$, longitude $1.11 \mathrm{~W})$. More than 400 acorns were obtained from the controlled cross, from which 278 seedlings were produced. A subset of 94 individuals were previously used for the construction of parental genetic maps (Barreneche et al, 1998) and 184 additional full sibs were genotyped for QTL mapping in the present study. The 278 seedlings were raised in a seedbed in the nursery until age 3, and they were then transplanted in a clonal bank as stool-beds. The spacing between the stool-beds was $1.5 \mathrm{~m} \times 1.5 \mathrm{~m}$. After 2 years following the transplantation, when the seedlings were 5 years old, each stool-bed was hedged at the level of the ground in late-February. The stool-beds stump sprouted in late April, and when the sprouts were fully elongated, cuttings were prepared for vegetative propagation. The cuttings consisted of stem segments about 10-12 cm long, comprising at least two internodes. They were dipped in a rooting hormone (Rhipozon AA 0.5) and transplanted in $80 \mathrm{~cm}^{3}$ containers with a $60 / 40$ mixture of peat/ perlite. The cuttings were then transferred into a greenhouse that was watered by a fog system. The first rooting occurred after 5 weeks, and more than $60 \%$ of the cuttings rooted within 2 months. The rooted cuttings were further transplanted into 41 containers (with a mixture of 2/1/2: peat/sand/pine bark) in September. They over-wintered in a greenhouse and grew outdoors in the nursery for an additional year. The procedure for vegetative propagation was used recurrently over 4 successive years. The QTL detection was carried out in two experiments.

Experiment 1: In total, 174 full sibs were successively propagated in summer 1997 and transplanted from the nursery to a field test located in Bourran (latitude $44.20 \mathrm{~N}$, longitude $0.24 \mathrm{~W}$, along the Garonne River) in southwest France. The experiment design comprised 36 incomplete blocks each containing single vegetative replicates of 30 full sibs. The whole experiment comprised 1080 cuttings (on average six vegetative replicates per full sib). The cuttings were planted in the spring 1999, and two fully elongated leaves were collected from each cutting in summer 1999. Leaf morphological data were adjusted to block effects prior to the detection of QTLs.

Experiment 2: This experiment comprised 216 full sibs of the same mapping pedigree. Vegetative propagation took place in spring 1998. Two leaves were collected in summer 1999 in the nursery from each of 1530 cuttings (on average seven vegetative replicates per full sib). The experimental design was considered as fully randomised.

\section{Assessment of leaf morphological traits}

In all, 15 morphological traits were assessed on all the leaves collected in the natural populations and in the two experiments. The measurements were made following the procedure indicated by Kremer et al (2002): lamina length (LL), petiole length (PL), lobe width (LW), sinus width (SW), length of lamina at widest point (WP), number of lobes (NL), number of intercalary veins (NV), basal shape of the lamina (BS), lamina shape $(\mathrm{OB}=\mathrm{WP} /$ $\mathrm{LL})$, petiole ratio $(\mathrm{PR}=(\mathrm{PL} /(\mathrm{PL}+\mathrm{LL})))$, lobe-depth ratio $(\mathrm{LDR}=(\mathrm{LW}-\mathrm{SW}) / \mathrm{LW})$, percentage venation $(\mathrm{PV}=\mathrm{NV} /$ $\mathrm{NL}$ ), lobe-width ratio ( $\mathrm{LWR}=\mathrm{LW} / \mathrm{LL})$. In addition to the morphological assessments, observation of pubescence (PU) was made at two different spots on the abaxial surface of each leaf: in the central part of the lamina (PUl) and along the veins (PUv). The measurements of pubescence along the veins were only made on the cuttings and not on the adult leaves. Observations of pubescence were made following Kissling's grading system (Kissling, 1980), ranging from 1 (no pubescence) to 6 (dense pubescence); pubescence was assessed using a stereo microscope.

\section{Statistical analysis}

Estimation of variance components in the natural population: The value of each morphological trait $\left(X_{i j k}\right)$ was decomposed according to the following twoway analysis of variance (ANOVA) model, using the 
OPEP Software (Baradat and Labbé, 1995):

$$
X_{i j k}=\mu+S_{i}+T_{i j}+L_{i j k}
$$

where $S_{i}$ stands for the effect of species $i, T_{i j}$ for the effect of tree $j$ within species $i$, and $L_{i j k}$ for the effect of leaf $k$ within tree $j$ and within species $i$.

In a second step, the subdivision was made separately within each species. Model (2) was successively used for $Q$. petraea and $Q$. robur

$$
Y_{j k}=\mu+T_{j}+L_{j k}
$$

where $Y_{j k}$ is the phenotypic value of a leaf morphological trait, $T_{i}$ the effect of tree $j$, and $L_{j k}$ is the effect of tree $j$ within tree $k$.

All sources of variation were considered as random. Consequently, the following ratios were calculated to account for the proportion of the total variation explained by different sources of variation.

$S=\sigma_{S}^{2} / \sigma_{X}^{2}$ derived from model (1) is an estimate of the variation explained by species differentiation, whereas $T=\sigma_{T}^{2} / \sigma_{\gamma}^{2}$ derived from model (2) represents the proportion of variation within a species that is due to tree variation within that species.

Estimation of variance components in the full-sibs pedigree: All data were analysed using the ANOVA with the OPEP Software (Baradat and Labbé, 1995). Since vegetative propagation was used to propagated the full sibs of the mapping pedigree, the subdivision of the phenotypic value $\left(Z_{i j}\right)$ of a cutting could be made with the following model in the two experiments:

$$
Z_{i j}=\mu+C_{j}+C u_{i j}
$$

where $C_{i}$ is the effect of clone $i$ and $C u_{i j}$ is the effect of cutting $j$ within clone $i$.

Based on the variance components obtained by the ANOVA (model 2), the repeatability could be calculated as

$$
R=\frac{\sigma_{C}^{2}}{\sigma_{C}^{2}+\frac{\sigma_{C u}^{2}}{n}}
$$

where $n$ is the number of cuttings for each clone.

\section{Construction of the linkage map}

The mapping strategy used in this study was the socalled double-pseudo-testcross mapping strategy (Grattapaglia and Sederoff, 1994). Based on the framework map that was obtained on the same pedigree but only on 94 full sibs (Barreneche et al, 1998), we extended the mapping to 278 individuals and mapped additional anchor markers on the total set of individuals. The additional mapping consisted in 38 microsatellites, six SCARs (Bodénès et al, 1996), and 13 AFLP primer-enzymes combinations (eight Eco/Mse and five Pst/Mse). Amplification fragment length polymorphism (AFLP) genotyping was performed as described by Vos et al (1995). AFLP markers were named according to the restriction enzyme used, the three selective nucleotides used on the amplification primers, the size of the band, and the quality of the scoring (1 (difficult to read) to 5 (very easy)). Microsatellites genotyping was performed using the primers developed by Kampfer et al (1998) and Steinkellner et al
(1997). AFLP fragments and microsatellites were separated by electrophoresis on an LI-COR (model 4000) DNA sequencer. Primers were labelled with the fluorescent infrared dye IRD800 (LI-COR, Lincoln, Neb.) and fragment analysis recorded by a laser system.

Mapmaker 2.0 (Lander et al, 1987) was used to infer linkage relationships among markers. To allow the detection of linkage of markers in repulsion phase, the data set was duplicated and recoded. First, markers were divided into linkage groups with the group command (parameters $\mathrm{LOD}=7 ; \theta=0.25$ ). Second, markers were ordered within the linkage group with the first-order command $(\mathrm{LOD}=3 ; \theta=0.40)$. The ordered marker sequences were confirmed using the ripple and LOD table commands. Kosambi's (1944) mapping function was then used to transform the recombination frequency between linked loci into centimorgan (cM) distances. The graphical presentation of linkage maps and QTL was obtained using the MapChart software version 2.0 (Voorrips, 2001).

\section{QTL detection}

The analytical method used to identify putative QTLs and to estimate their phenotypic effect was composite interval mapping (CIM; Jansen and Stam, 1994; Zeng, 1994), which is an extension of interval mapping (IM; Lander and Botstein, 1989). IM calculates the likelihood score for a putative QTL located at any position within an interval flanked by two adjacent markers. CIM extends this method by fitting the most significant markers outside the interval into the model, allowing more accuracy and efficiency of QTL mapping (Zeng, 1994). The MultiQtl software (Britvin et al, 2001; http://esti.haifa.ac.il/ poptheor) was used with no extended parameters (no LOD normalization and no missing data restoration). The SD for each QTL position was estimated by bootstrap (Visscher et al, 1996) with 1000 samplings. Empirical statistical significance thresholds for declaring the presence of a QTL were determined by permutations of the data set (Churchill and Doerge, 1994). In all, 1000 different samplings were generated from the actual data by shuffling the trait values with respect to the marker genotypes. Each individual genotyped was randomly assigned to one of the trait values from the sample. In the single QTL model, permutations permitted the null hypothesis of no QTL contributing to the trait to be tested.

Since the permutations tests were calculated at the chromosome level, we further computed the corresponding Type I error rate at the whole genome level. The relationship between Type I error rate at the genome level $\left(\alpha_{\mathrm{g}}\right)$ and Type I error rate at the chromosome level $\left(\alpha_{\mathrm{chr}}\right)$ is as follows:

$$
\alpha_{\mathrm{chr}}=1-\left\{1-\left[1-\left(1-\alpha_{\mathrm{g}}\right)^{1 / M_{1}}\right]\right\}^{m}
$$

where $M$ is the total number of markers used for the QTL detection on each map and $m$ the number of markers in the linkage group.

The QTL detection was carried out separately for each parental map in both the experiments.

For each combination of morphological trait and marker, the following ANOVA model was used to subdivide the variance components of the clonal means 
in the QTL detection:

$$
\bar{Z}_{i j}=\mu+M_{i}+C_{i j}
$$

where $\bar{Z}_{i j}$ is the clonal mean as derived from model (3), $M_{i}$ the marker effect, and $C_{i j}$ the effect of clone $j$ (within the marker class).

If $\sigma_{\bar{Z}}^{2}$ is the variance of the clonal means $\left(\sigma_{\bar{Z}}^{2}=\sigma_{C}^{2}+\sigma_{C u}^{2} / n\right)$, and if $P$ is the proportion of $\sigma_{\bar{Z}}^{2}$ explained by the QTL, then the proportion $Q$ of the clonal variance explained by the QTL is $Q$ with $Q=P / R$

\section{Results}

\section{Subdivision of the phenotypic variation in the natural population}

All sources of variation contributed significantly to the diversity of leaf morphology as shown by the different ANOVAs computed. However, the contributions of the different sources were quite different according to the traits considered (Table 1). For size-related traits, such as lamina length (LL) and lobe width (LW), species differences represent only a minor part of the total variation. Conversely, more than $80 \%$ of the total variation was due to species subdivision for petiole length (PL) and petiole ratio (PR). To a lesser degree, venation (NV, 67\% and $\mathrm{PV}, 70 \%)$, pubescence (Pul, 77\%), sinus width (SW, 59\%), and basal shape of lamina (BS, 72\%) exhibited important species variation. However, despite the important species variation, the range of variation within a species significantly overlapped the range of variation for the other species. As an example, Q. petraea exhibited a PL varying between 3 and $33 \mathrm{~mm}$, whereas PL varied between 0 and $12 \mathrm{~mm}$ in $Q$. robur. For pubescence, $Q$. robur is often reported as glabrous and indeed $84 \%$ of the leaves did not exhibit any pubescence,

Table 1 Partitioning of leaf morphology variation in the natural population

\begin{tabular}{lllllll}
\hline Trait & \multicolumn{2}{c}{ Q. petraea } & & \multicolumn{3}{c}{ Q. robur } \\
\cline { 2 - 3 } & Mean & $\mathrm{T}$ & & Mean & $\mathrm{T}$ & $\mathrm{S}$ \\
\hline LL (mm) & 91.4 & 0.59 & & 77.5 & 0.64 & 0.23 \\
PL (mm) & 16 & 0.70 & & 4.4 & 0.52 & 0.81 \\
LW (mm) & 28.2 & 0.61 & & 4.5 & 0.63 & 0.14 \\
SW (mm) & 20.5 & 0.62 & & 13.4 & 0.50 & 0.59 \\
WP (mm) & 49.7 & 0.42 & & 44.4 & 0.50 & 0.08 \\
NL & 11.2 & 0.52 & & 8.7 & 0.50 & 0.51 \\
NV & 0.35 & 0.32 & & 3.1 & 0.49 & 0.67 \\
BS & 3.9 & 0.47 & & 6.8 & 0.48 & 0.72 \\
PU1 & 3.4 & 0.58 & & 1.2 & 0.74 & 0.77 \\
OB (\%) & 54.1 & 0.16 & 57.3 & 0.17 & 0.07 \\
PR (\%) & 14.8 & 0.68 & & 5.4 & 0.50 & 0.84 \\
LDR (\%) & 26.7 & 0.47 & & 44.5 & 0.44 & 0.67 \\
PV (\%) & 3.32 & 0.34 & & 36.0 & 0.48 & 0.70 \\
LWR (\%) & 30.8 & 0.51 & 31.6 & 0.40 & 0.02 \\
\hline
\end{tabular}

$S=\sigma_{S}^{2} / \sigma_{X}^{2}$ (between species variance/total variance, see model (1) in the text), $T=\sigma_{T}^{2} / \sigma_{Y}^{2}$ (between tree variance/total variance, see model (2) in the text), $L L=$ lamina length, $P L=$ petiole length, $\mathrm{LW}=$ lobe width, $\mathrm{SW}=$ sinus width, $\mathrm{WP}=$ length of lamina at widest point, $\mathrm{NL}=$ number of lobes, $\mathrm{NV}=$ number of intercalary veins, $\mathrm{BS}=$ basal shape of the lamina, $\mathrm{OB}=$ lamina shape, $\mathrm{PR}=$ petiole ratio, $\mathrm{LDR}=$ lobe-depth ratio, $\mathrm{PV}=$ percentage venation, $\mathrm{LWR}=$ lobe-width ratio, PUl pubescence on the central part of the lamina. but $16 \%$ of the leaves did exhibit hairs on the abaxial surface of the lamina. Similarly, leaves of $Q$. petraea have usually only a few intercalary veins. Indeed, only $75 \%$ of the leaves did not show any intercalary veins in Q. petraea and this percentage amounted to $5 \%$ in $Q$. robur. The subdivision of variation within a species indicated that the traits that showed high species differentiation also exhibited an important within-species tree-to-tree variation (Table 1).

\section{Subdivision of phenotypic variation in the mapping pedigree}

In experiment 1 , data were first adjusted to block effects prior to using ANOVA model (3), whereas in experiment 2, data were directly analysed using ANOVA model (3). All phenotypic values, except PUv, were normally distributed as tested by the Box and Cox method (Box and Cox, 1964). The clonal effect was significant in all ANOVAs, except for OB and LWR in experiment 1 (data not shown).

Repeatability values were slightly higher in experiment 2, as the result of higher environmental variance due to the heterogeneity of environmental conditions in the field test (experiment 1, Table 2). Pubescence (either PUl or PUv) had the highest repeatability, and $\mathrm{OB}$ or LWR exhibited the lowest genetic control in both experiments. Overall, morphological traits reported to be strongly involved in species differences (PL, SW, NV, BS, PU, and their derived variables PR, LDR, PV; see Table 1) were also among those that had the largest repeatability values, especially in experiment 2.

\section{Correlations between leaf morphological traits}

Correlations between tree values derived from ANOVA model (2) in the natural population (Table 3a), or clone

Table 2 Mean values and repeatability of leaf morphology traits in the mapping pedigree

\begin{tabular}{|c|c|c|c|c|}
\hline \multirow[t]{2}{*}{ Trait } & \multicolumn{2}{|c|}{ Experiment 1} & \multicolumn{2}{|c|}{ Experiment 2} \\
\hline & $M e a n \pm S D$ & $\mathrm{R}$ & $M e a n \pm S D$ & $\mathrm{R}$ \\
\hline LL (mm) & $58.5 \pm 15.2$ & 0.56 & $69.8 \pm 20.4$ & 0.66 \\
\hline PL (mm) & $2.6 \pm 0.86$ & 0.3 & $3.2 \pm 1.0$ & 0.74 \\
\hline LW (mm) & $17.8 \pm 5.19$ & 0.54 & $20.7 \pm 7.23$ & 0.65 \\
\hline SW (mm) & $6.4 \pm 2.5$ & 0.62 & $8.4 \pm 3.8$ & 0.73 \\
\hline $\mathrm{WP}(\mathrm{mm})$ & $34.6 \pm 11.9$ & 0.49 & $41.9 \pm 14.8$ & 0.65 \\
\hline NL & $7.7 \pm 1.7$ & 0.58 & $8.5 \pm 1.9$ & 0.75 \\
\hline NV & $5.8 \pm 2.3$ & 0.49 & $4.2 \pm 1.9$ & 0.84 \\
\hline BS & $5.1 \pm 1.4$ & 0.53 & $4.6 \pm 1.7$ & 0.68 \\
\hline Puv & $1.5 \pm 0.74$ & 0.8 & $1.7 \pm 0.93$ & 0.90 \\
\hline PUl & $2.8 \pm 0.80$ & 0.74 & $2.2 \pm 0.92$ & 0.84 \\
\hline OB (\%) & $59.6 \pm 18.8$ & 0 & $61.1 \pm 28.5$ & 0.44 \\
\hline PR (\%) & $4.4 \pm 1.7$ & 0.38 & $4.5 \pm 1.6$ & 0.63 \\
\hline LDR (\%) & $62.9 \pm 13.0$ & 0.51 & $58.9 \pm 13.1$ & 0.70 \\
\hline PV (\%) & $76.7 \pm 37.5$ & 0.17 & $52.9 \pm 37.2$ & 0.73 \\
\hline LWR (\%) & $31.0 \pm 9.87$ & 0.07 & $30.0 \pm 11.4$ & 0.43 \\
\hline
\end{tabular}

$\mathrm{SD}=$ standard deviation, $R=$ repeatability of the clonal mean, $\mathrm{LL}=$ lamina length, $\mathrm{PL}=$ petiole length, $\mathrm{LW}=$ lobe width $\mathrm{SW}=$ sinus width, $\mathrm{WP}=$ length of lamina at widest point $\mathrm{NL}=$ number of lobes, $\mathrm{NV}=$ number of intercalary veins, $\mathrm{BS}=$ basal basal shape of the lamina, $\mathrm{OB}=$ lamina shape, $\mathrm{PR}=$ petiole ratio, $\mathrm{LDR}=$ lobe-depth ratio, $\mathrm{PV}=$ percentage venation, $\mathrm{LWR}=$ lobewidth ratio, PUl pubescence on the central part of the lamina, PUv pubescence along the veins. 
Table 3 Matrix of correlation coefficients between leaf morphological traits calculated

\begin{tabular}{lrrrrr}
\hline & $P L$ & $S W$ & $N V$ & $B S$ & $P u l$ \\
\hline (a) Natural population & a & & & & \\
PL & & $\mathbf{0 . 5 8}$ & -0.11 & $-\mathbf{0 . 2 0}$ & $-\underline{\mathbf{0 . 2 1}}$ \\
SW & $\mathbf{0 . 2 3}$ & & -0.05 & -0.05 & $-\underline{\mathbf{0 . 2 7}}$ \\
NV & -0.01 & -0.04 & & 0.09 & $-\mathbf{0 . 2 3}$ \\
BS & -0.04 & 0.01 & -0.09 & & -0.001 \\
PUl & -0.05 & -0.06 & 0.07 & -0.03 &
\end{tabular}

(b) Two experiments of the mapping pedigree of $Q$. robur ${ }^{\mathrm{b}}$

$\begin{array}{lrrrrr}\text { PL } & \mathbf{0 . 1 7} & \mathbf{0 . 2 6} & \mathbf{0 . 1 8} & -\mathbf{0 . 2 0} & -0.03 \\ \text { SW } & \mathbf{0 . 4 3} & \mathbf{0 . 2 4} & -\mathbf{0 . 4 6} & 0.06 & -0.05 \\ \text { NV } & 0.13 & -0.05 & 0.09 & \mathbf{0 . 2 1} & 0.01 \\ \text { BS } & -\mathbf{0 . 2 4} & 0.11 & 0.13 & 0.11 & -0.01 \\ \text { PUl } & -0.13 & -0.13 & -\mathbf{0 . 3 2} & 0.11 & \mathbf{0 . 2 0}\end{array}$

$\mathrm{NL}=$ number of lobes, $\mathrm{PL}=$ petiole length, $\mathrm{NV}=$ number of inter calary veins, $\mathrm{SW}=$ sinus width, $\mathrm{PUl}=$ pubescence in the central part of the lamina. Underlined values correspond to correlations that exhibit opposite signs at the inter- and intraspecific level (see text), values in bold are significant at $P \leqslant 5 \%$.

${ }^{\text {a }}$ The correlations are based on the tree effect (model 2). Above the diagonal, values correspond to $Q$. petraea, Below the diagonal, values correspond to Quercus robur.

${ }^{\mathrm{b}}$ Correlations are based on the clone effect (model 3). Above the diagonal, genetic correlation for experiment 1 . Below the diagonal, genetic correlation for experiment 2. Diagonal, genetic correlation between experiments 1 and 2 .

values derived from ANOVA model (3) in the mapping pedigree (Table $3 b$ ) were calculated. Size-related leaf characters (LL, SW, LW, WP) were significantly correlated, mostly as a result of the common size effect (data not shown). We focused our attention here only on those traits that exhibited a high between-species variation according to Table 1 (eg, PL, SW, NV, BS, PU). The values of these five characters were all significantly different between $Q$. petraea and $Q$. robur. Q. petraea has larger petioles (PL), fewer intercalary veins (NV), less pronounced sinuses (SW), sharper basal leaf lamina (BS), and more pubescence (PU) than $Q$. robur (Table 1). One can therefore consider these five characters to be correlated at the interspecific level.

Correlations among these characters are less pronounced at the intraspecific level. In the natural populations, only five correlations among the 10 pairwise associations were significant in Q. petraea, and only one in $Q$. robur (Table 3a). In the mapping pedigree, where the computed correlations represent mostly genetic correlations, five of the 10 correlations were significant in experiment 1 and three in experiment 2 (Table 3b). A more intriguing feature of the significant correlations is that in some cases, the sign of the correlation is different between the inter- and intraspecific levels. Among the 14 significant correlations (Table $3 a$ and $b$ ), three changed sign from the inter- to the intraspecific level. This is illustrated by the correlation between PL and NV. The leaves of $Q$. robur have smaller petioles (PL) and more intercalary veins (NV, Table 1). However, within the mapping pedigree in $Q$. robur, clones that had smaller petioles tended to have fewer intercalary veins (Table $3 \mathrm{~b}$ ). Correlations of opposite sign between the inter- and intraspecific levels also occurred in Q. petraea (Table 3a).

\section{Linkage map for QTL detection}

The 13 AFLP primer-enzyme combinations provided 201 markers segregating in a 1:1 ratio. Among them, $4 \%$ showed a significant deviation $(P<1 \%)$ from Mendelian segregation and were discarded. The genotyping of the offspring also included 38 microsatellites and six SCARs. Nine additional RAPD markers were selected from the reference map (Barreneche et al, 1998) and were included to fill gaps in some linkage groups. Among the 254 markers obtained, a subset of 128 markers (84 AFLP, 34 microsatellites, one SCAR, nine RAPD), evenly distributed across the genome, were finally selected to construct the QTL map. The two maps shared 19 microsatellites. The female framework map was composed of 75 markers over a total distance of $890 \mathrm{cM}$, covering $75 \%$ of the genome (estimated total length is $1192 \mathrm{cM}$ (Barreneche et al, 1998)) with an average spacing between markers of $14 \mathrm{cM}$. The male framework map comprised 72 markers over a total distance of $929 \mathrm{cM}$, covering $75 \%$ of the genome (estimated total length is $1235 \mathrm{cM}$ ) with an average marker spacing of $15.5 \mathrm{cM}$.

\section{QTL mapping}

No QTL was detected for two traits (LW, OB) among the 15 leaf morphological traits assessed when the probability threshold was set at 5\% at the genome level. Genetic variation for LW and OB was low as shown by their repeatability values (Table 2 ).

For the remaining 13 traits, between one and two significant QTLs were detected, which on average explained from 10.7 to $13.8 \%$ of the clonal mean variance (Table 4). Overall, the proportion of phenotypic variance explained by the QTLs detected in this pedigree remains moderate, despite the high repeatability values of the traits, especially in experiment 2 . There was no obvious relationship between the level of the repeatability and the number of QTLs, or the proportion of phenotypic variance explained by the QTLs. For example, in the case of pubescence (PUv or PUl), which exhibited the highest repeatability (Table 2), two QTLs were detected only in experiment 1, with each QTL explaining between 12.9 and $17.2 \%$ of the phenotypic variance (Table 4 ). For six traits (PL, SW, NL, NV, LDR, PV), QTLs were detected in both experiments. Interestingly, these traits are strongly involved in species differentiation. When considering only the five traits that exhibited the highest species differentiation (eg the same traits presented in Table 3: PL, SW, NV, BS, PU), their QTLs were located on six different linkage groups (LG1, LG3, LG4, LG5, LG11, LG12) when bulking the information over both experiments (Table 4, Figure 1). Some of these QTLs were detected on the same linkage group in both experiments (for PL on LG1, SW on LG 3). Colocalisation of QTLs of at least two different traits involved in species differentiation can be seen on LG1 (PL, PU) and LG3 (NV, SW). A clustering of QTLs controlling raw or derived traits involved in species differentiation can clearly be seen on LG3 (PV, NV, LDR, SW).

When the Type I error rate for the QTL detection was relaxed from 5\% at the genome level to $5 \%$ at the chromosome level, then the former clusters of QTLs involved in species differentiation were reinforced by the 
Table 4 QTL detection summary for the leaf morphological traits

\begin{tabular}{|c|c|c|c|c|c|c|c|c|c|}
\hline Traits & $L G$ & $\mathrm{~N}$ & Lod & $\alpha_{\mathrm{chr}}$ & $P 1$ & $P 2$ & $C I$ & $\mathrm{D}$ & $\mathrm{P}$ \\
\hline \multicolumn{10}{|l|}{ Experiment 1} \\
\hline PL & $1 \mathrm{f}$ & 124 & 3.9 & 0.004 & 55.4 & 46.7 & 20.2 & 0.32 & 13.6 \\
\hline PR & $10 \mathrm{f}$ & 134 & 3.2 & 0.005 & 63.1 & 60.9 & 18.5 & 0.48 & 9.7 \\
\hline LWR & $10 \mathrm{f}$ & 131 & 2.8 & 0.005 & 68.9 & 65.5 & 19 & 2.26 & 9.9 \\
\hline SW & $3 \mathrm{f}$ & 126 & 3.7 & 0.002 & 22.3 & 22.1 & 6.9 & 1.00 & 15.5 \\
\hline SW & $3 \mathrm{~m}$ & 137 & 3.6 & 0.003 & 19.3 & 17.2 & 9.2 & 0.81 & 10.9 \\
\hline LDR & $3 \mathrm{f}$ & 126 & 3.7 & 0.002 & 20.5 & 18.2 & 16.3 & -4.99 & 14.5 \\
\hline LDR & $3 m$ & 137 & 3.0 & 0.003 & 19.1 & 18.5 & 7.9 & -3.84 & 9.9 \\
\hline PUl & $12 \mathrm{f}$ & 110 & 4.8 & 0.003 & 14.9 & 17.6 & 11.9 & 0.37 & 17.2 \\
\hline PUl & $1 \mathrm{~m}$ & 108 & 3.0 & 0.003 & 29.3 & 30.8 & 12.9 & -0.33 & 12.9 \\
\hline NL & $2 \mathrm{f}$ & 89 & 3.9 & 0.005 & 67 & 50.7 & 39.7 & 0.94 & 22.9 \\
\hline NV & $3 \mathrm{f}$ & 126 & 4.7 & 0.002 & 20.2 & 15.8 & 15.7 & -0.91 & 16.4 \\
\hline PV & $3 f$ & 126 & 5.7 & 0.002 & 20.4 & 18.3 & 12.8 & -12.19 & 21.7 \\
\hline Mean values & & & & & & & & & 13.8 \\
\hline \multicolumn{10}{|l|}{ Experiment 2} \\
\hline LL & $11 \mathrm{f}$ & 171 & 3.2 & 0.004 & 2.7 & 7.3 & 27.8 & 6.64 & 8.8 \\
\hline LL & $6 \mathrm{~m}$ & 184 & 2.5 & 0.003 & 26 & 25.3 & 10.3 & -5.70 & 6 \\
\hline PL & 1f & 156 & 4.2 & 0.004 & 39 & 44.2 & 17.1 & 0.41 & 11.2 \\
\hline PL & $11 \mathrm{f}$ & 171 & 3.4 & 0.004 & 17.7 & 19.4 & 23.3 & 0.36 & 7.9 \\
\hline PR & 1f & 165 & 3.6 & 0.004 & 9 & 12.2 & 25.5 & 0.66 & 11.8 \\
\hline SW & $3 \mathrm{f}$ & 162 & 3.1 & 0.002 & 17.9 & 18.3 & 5.4 & 1.51 & 8.4 \\
\hline SW & $3 m$ & 160 & 2.5 & 0.003 & 43.2 & 27.6 & 33.1 & 1.61 & 9.7 \\
\hline LDR & $3 \mathrm{f}$ & 162 & 7.1 & 0.002 & 17.9 & 17.7 & 3.0 & -6.14 & 19.1 \\
\hline LDR & $3 m$ & 160 & 4.5 & 0.003 & 41.1 & 34.2 & 21 & -6.41 & 8.2 \\
\hline BS & $4 m$ & 131 & 2.6 & 0.004 & 86.3 & 74.4 & 33.7 & -0.54 & 8.4 \\
\hline WP & $11 \mathrm{f}$ & 171 & 3.0 & 0.004 & 5.2 & 9.6 & 30.4 & 4.69 & 8.4 \\
\hline NL & $8 \mathrm{~m}$ & 166 & 3.1 & 0.005 & 11.6 & 16 & 34.1 & -0.71 & 8.4 \\
\hline NV & $5 \mathrm{f}$ & 168 & 7.4 & 0.005 & 31.4 & 32.2 & 14.1 & 1.00 & 17.6 \\
\hline PV & $5 \mathrm{f}$ & 168 & 6.2 & 0.005 & 31.4 & 30.7 & 6.1 & 15.53 & 15.7 \\
\hline Mean values & & & & & & & & & 10.7 \\
\hline
\end{tabular}

$\mathrm{LG}=$ linkage group (m: male map; f: female map), $N=$ number of individuals genotyped for the flanking markers, Lod $=$ highest LOD in the interval, $\alpha_{\mathrm{chr}}=$ theoretical $P$-value at the chromosome level corresponding to the $P$-value of $5 \%$ at the genome level, P1=position of the highest LOD score from the composite Interval mapping, P2 = position of the mean value for maximum LOD score after bootstrap analysis (1000 bootstrap samples), $\mathrm{CI}=$ QTL confidence interval (95\%) based on the 1000 bootstrap samples, $D=$ size of effect, $P=$ percentage of the clonal mean variance explained by the QTL.

addition of suggestive QTLs for other informative morphological traits (Figure 2):

- on LG1F (c. 30 cM) : PU11, PL1, PL2, BS2, and PUl1 on LG1M;

- on LG3F (c. 20 cM): NV1, NV2, PL2, SW1, SW2, and BS2, SW1, SW2 on LG3M;

- on LG4M (c.10 cM): PL1 and PUv2;

- on LG6M (c. 40 cM): PU12, SW1, and PU11 on LG6F;

- on LG9F (c. $10 \mathrm{cM}$ ): PUv1, PUv2, SW1, and BS2 on LG9M;

- on LG12F (c. 30 cM): PUl1 and NV2.

Two additional ones were also identified (data not shown):

- on LG5F (c. $40 \mathrm{cM}$ ): NV2 and SW1 on LG5M;

- on LG7F (c. 30 cM): PUv1, PUv2, and PU12 on LG7M.

\section{Discussion}

QTL mapping as a method for detecting genomic regions involved in oak species differentiation

As leaf morphology traits are of low economic importance, they have seldom been studied for estimating genetic variances or QTL detection. Most of the 15 traits assessed exhibited high repeatability values. Leaf pubescence was the trait with highest repeatability, and in general there was a trend towards larger repeatabilities for those traits that show higher species differentiation. QTLs were detected for 13 traits among the 15 studied. The QTLs explained on average 11.1-13.8\% of the clonal mean variance. Assuming dominance is zero, these values can be translated in the proportion of additive variance explained by the QTLs, varying between 9 and $66 \%$ in experiment 1 , and 5 and $14 \%$ in experiment 2 . These values can be compared to other reported studies on leaf morphological traits providing estimates of the proportion of the additive variance explained by the QTLs: from 2 to $37 \%$ in Brassica oleracea (Lan and Paterson, 2001) and from 5 to $52 \%$ in Gossypium hirsutum and G. barbadense (Jiang et al, 2000). The major objective of this research was to map genomic regions involved in species differentiation, by locating QTLs involved in phenotypic differences between $Q$. petraea and $Q$. robur. We chose leaf morphology traits as they have been explored in many studies for species identification. Indeed, we reanalysed the variation of 15 of these traits and showed that five of them exhibit important variation among the two species. The QTL strategy should not, however, be considered as an exhaustive way of identifying informative regions. First 


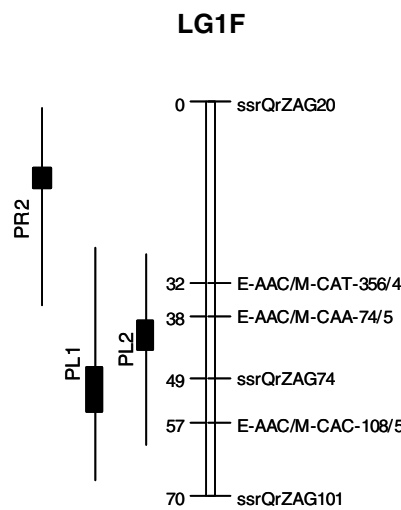

\section{LG1M}

LG2F

LG3F

LG3M
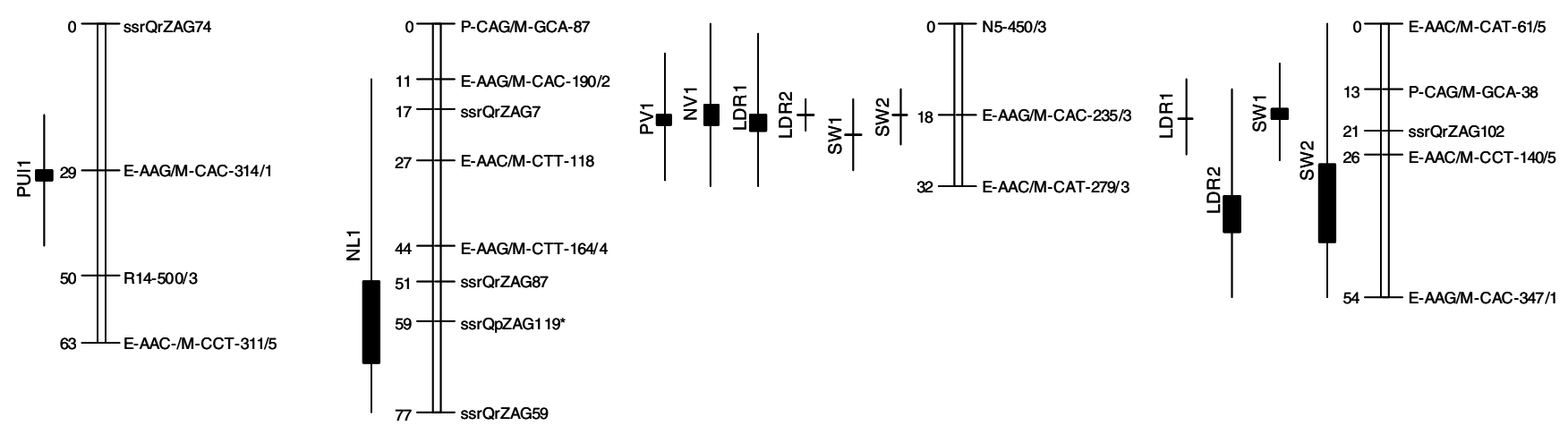

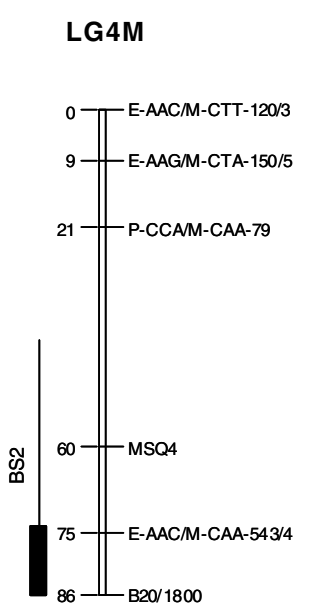

LG12F

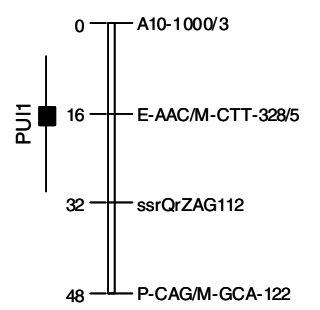

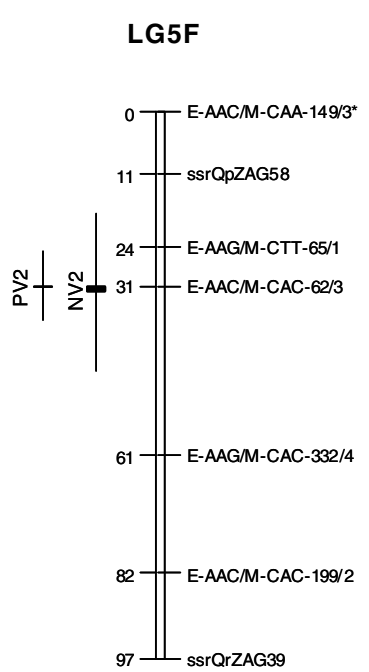

\section{LG6M}

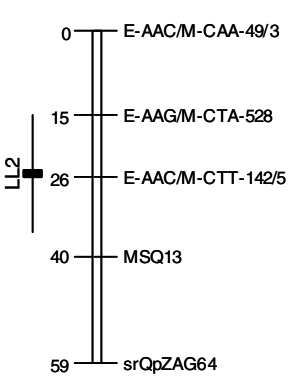

LG8M
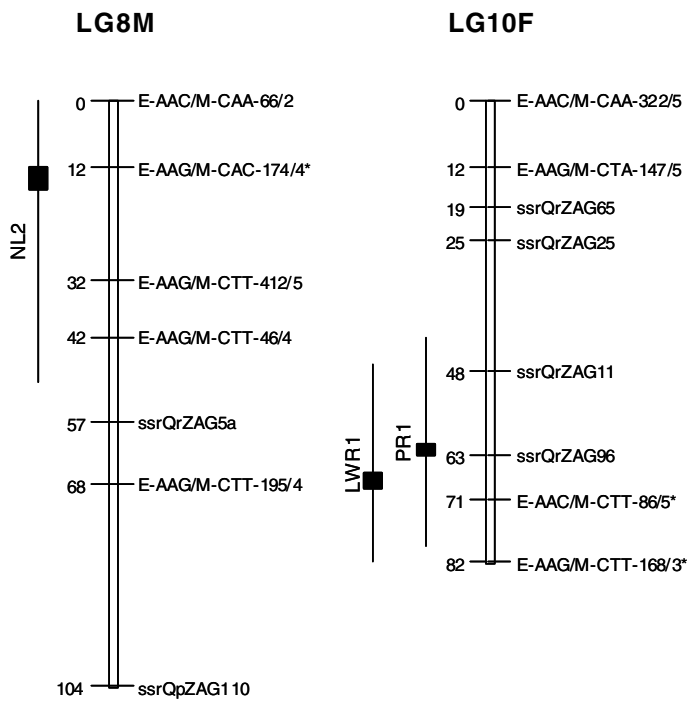

\section{LG11F}

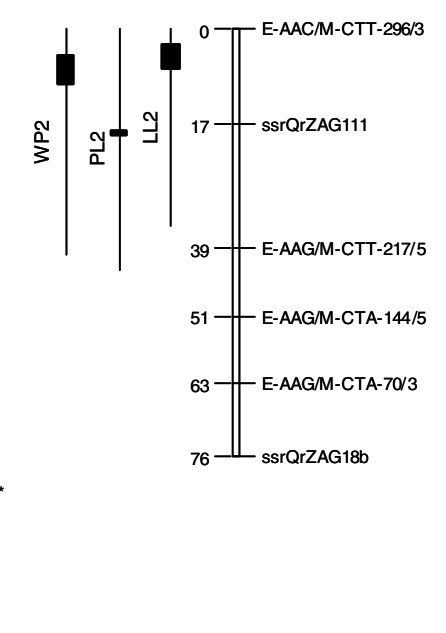


of all, our mapping pedigree was an intraspecific full-sib family, which may have reduced the chances of detecting informative QTLs. Some of these loci may be fixed within a species for different alleles and exhibit complete interspecific differentiation. Hence, they would not segregate in a full-sib intraspecific family. Ideally, an interspecific mapping pedigree (either F2 or backcross) would be necessary to detect these QTLs, for example, Drosophila (Zeng et al, 2000) and Mimulus (Lin and Ritland, 1997). However, due to experimental constraints related to the length of generations, F2 or backcrosses are not available in oaks. Second, some of the loci may be missed by chance just because they are not polymorphic between the two parents of the mapping pedigree. Finally, if QTLs controlling morphological traits are numerous and if each one contributes only a small part of the phenotypic variation of the trait, then it can also be missed because the family size of our mapping pedigree was too low (the so-called Baevis effect; Beavis, 1995), despite the vegetative propagation used to increase the power for QTL (Bradshaw and Foster, 1992). Neither of these hypotheses can be completely excluded. However, the existing data of genetic diversity within the complex of the two species (Kremer and Petit, 1993; Mariette et al, 2002) suggest that they are highly polymorphic, and that fixation within species has never been found for nuclear markers that were polymorphic within the complex. Even when the genomes of the two species were screened for numerous markers (RAPDs, Bodénès et al, 1996 or AFLPs, Mariette et al, 2002), polymorphism was always shared among the two species. Hence, we expected that polymorphism for QTLs involved in species differentiation is likely to be shared as well. High levels of polymorphism in oaks increase the chances of detecting QTLs in a single full-sib family, but additional experiments in other pedigrees need to be implemented to complete the detection. Finally, larger family sizes would be needed to increase statistical power of QTL detection of morphological traits, as our results indicated that most QTLs contributed individually only a minor part of the phenotypic variation of the trait.

Distribution of genomic regions differentiating oak species When the analysis was restricted to the five morphological characters involved in species differentiation, we found that their QTLs were distributed on six linkage groups when the Type I error rate was set at 5\% for the whole genome, and on nine linkage groups when it was set at $5 \%$ for the chromosome level. Recalling that our method provides an incomplete number of informative QTL, we may conclude that species differentiation occurs at multiple sites within the genome and is not confined to a few spots with limited recombination. Our results in oaks contribute to the heterogeneity of results in the same area that have recently been reviewed by Orr
(2001). In a synthesis of QTLs detections oriented towards species differentiation, Orr reported that the number of informative QTLs varied between one and 20. Examples of the heterogeneity of results are given in Drosophilae (Drosophila simulans and D. mauritiana; Zeng et al, 2000) or Mimulus (Lin and Ritland, 1997). In both cases, depending on the traits measured, there was a large variation in the number of QTLs. Part of the inconsistency could be explained by experimental constraints, as QTL detection is highly dependent on sample sizes in mapping pedigrees (Wilcox et al, 1997), as is illustrated in this study by the differences observed between the two experiments. Given that sample sizes of mapping pedigrees in the few hundred usually tend to inflate the contribution of the detected QTLs, we may conclude that a larger number of informative genomic regions for species differentiation exists within the genome. In addition, our results, based on an underestimate of these regions, clearly indicated that species differentiation is spread throughout the genome. However, QTLs involved in different discriminant morphological characters tend to be distributed in clusters. No conclusion can be drawn as to whether these clusters correspond to a single locus with pleiotropic effects or to linked loci contributing to different morphological traits. The occurrence of the clusters is also a direct expression of the correlations among traits, suggesting that they may contribute to variation of the morphological trait due to linkage disequilibrium. A further question is whether interactions among these clusters (epistatic effects) or interlocus disequilibria may also contribute to the overall differentiation among the two species.

\section{Acknowledgements}

The study has been carried out with the financial support from the Commission of the European Communities, Community research programme 'Quality of life and Management of Living resources' (Project OAKFLOW QLK5-2000-00960). We are very grateful to Guy Roussel for making the intraspecific cross, to Maria Evangelista Bertocchi for the vegetative propagation of the offspring, to Jean-Marc Louvet and Alexis Ducousso for field collection and assessments of morphological traits, and to the crew of the INRA nursery at Pierroton (Olivier Lagardère, Bernard Montoussé, Laurent Salera) for the helpful assistance in field work.

\section{References}

Aas G (1993). Taxonomical impact of morphological variation in Quercus robur and Q. petraea: a contribution to the hybrid controversy. Ann Sci For 50(Suppl. 1): 107s-113s.

Bacilieri R, Ducousso A, Kremer A (1995). Genetic, morphological, ecological and phenological differentiation between Quercus petraea (Matt.) Liebl. and Quercus robur L. in a mixed stand in the northwest of France. Silvae Genet 44: 1-10.

Figure 1 Distribution of QTLs for leaf morphology traits with a threshold fixed to 5\% at the genome level: lamina length (LL), number of lobes (NL), petiole length (PL), number of intercalary veins (NV), sinus width (SW), petiole ratio (PR), lobe-depth ratio (LDR), percentage venation (PV), length of lamina at widest point (WP), pubescence in the central part of the lamina (PUl), lobe-width ratio (LWR). Index 1 corresponds to QTLs detected in experiment 1, index 2 corresponds to QTLs detected in experiment 2. Each QTL is delineated by the position of the highest LOD score and the bootstrap mean value of the highest LOD score. Confidence intervals of their position based on 1000 bootstrap samples are indicated as lines. 


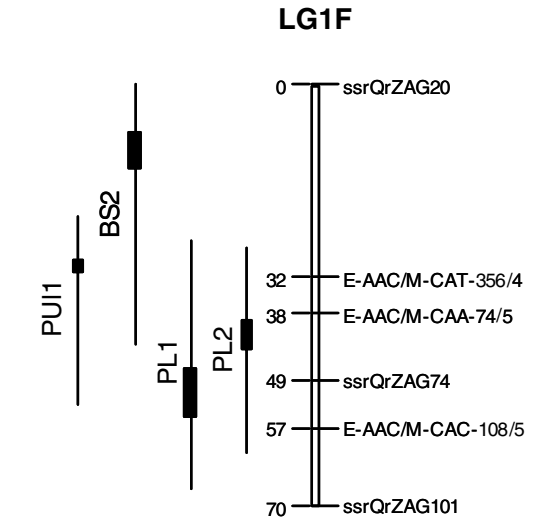

LG1M

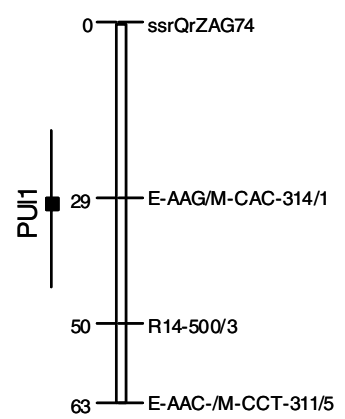

\section{LG3M}

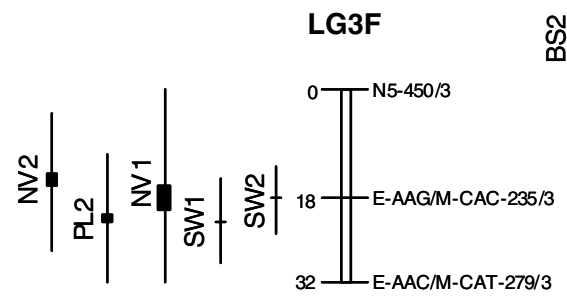

कू.

LG6F

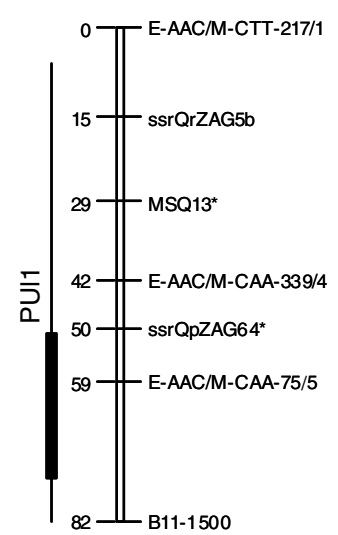

LG6M

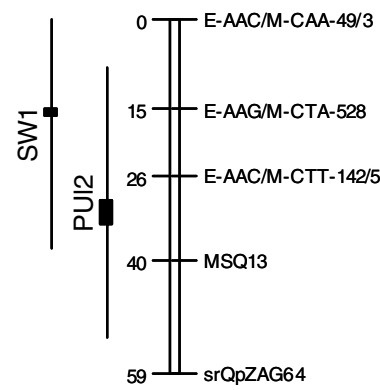

LG4F
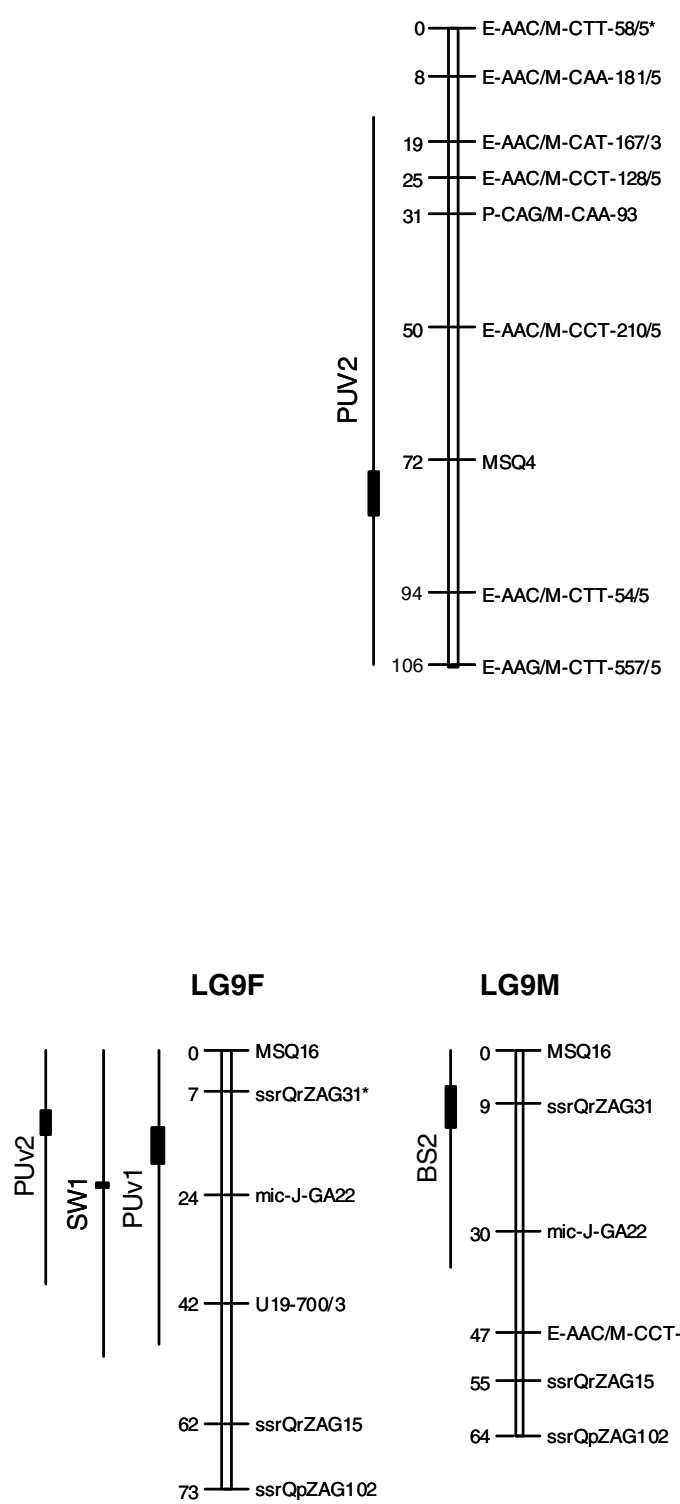

\section{LG9M}

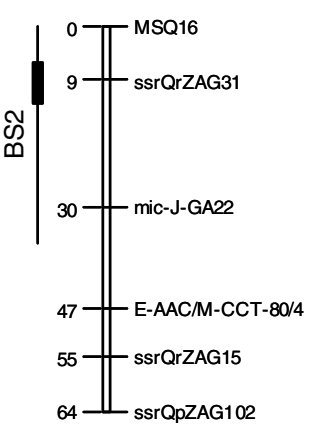

LG4M

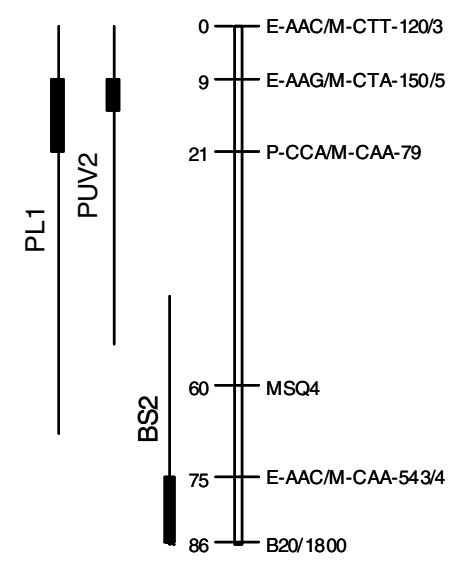

LG12F

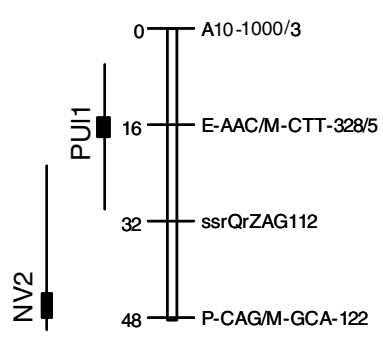


Bacilieri R, Ducousso A, Petit RJ, Kremer A (1996). Mating system and asymmetric hybridization in a mixed stand of European oaks. Evolution 50: 900-908.

Baradat P, Labbé T (1995). Opep, un logiciel intégré pour l'amélioration des plantes pérennes. In: Traitements statistiques des essais de sélection. Stratégies d'amélioration des plantes pérennes, Cirad: Montpellier (France), pp 303-330.

Barreneche T, Bahrman N, Kremer A (1996). Two dimensional gel electrophoresis confirms the low level of genetic differentiation between Quercus robur L. and Quercus petraea (Matt.) Liebl. Forest Genet 3: 89-92.

Barreneche $\mathrm{T}$, Bodénès $\mathrm{C}$, Lexer $\mathrm{C}$, Trontin JF, Fluch $\mathrm{S}$, Streiff $\mathrm{R}$ et al (1998). A genetic linkage map of Quercus robur $\mathrm{L}$. (pedunculate oak) based on RAPD, SCAR, microsatellite, minisatellite, isozyme and 5S rDNA markers. Theor Appl Genet 97: 1090-1103.

Beavis WD (1995). The power and deceit of QTL experiments: lessons from comparative studies. In: Proceedings of the 49th Annual Corn and Sorghum Industry Research Conference. Chicago, IL. pp 250-266.

Becker M, Levy L (1990). Le point sur l'écologie comparée du chêne sessile (Quercus petraea (Matt.) Liebl., et le chêne pédonculé (Quercus robur L.). Rev For Fr 42: 148-154.

Bodénès C, Joandet S, Laigret F, Kremer A (1997). Detection of genomic regions differentiating two closely related oak species Quercus petraea (Matt.) Liebl. and Quercus robur L. Heredity 78: 433-444.

Bodénès C, Laigret F, Kremer A (1996). Inheritance and molecular variations of PCR-SSCP fragments in pedunculate oak (Quercus robur L.). Theor Appl Genet 93: 348-354.

Box GEP, Cox DR (1964). An analysis of transformation. J Am Stat Asso 39: 357-365.

Bradshaw HD, Foster GS (1992). Marker-aided selection and propagation systems in trees: advantages of cloning for studying quantitative inheritance. Can J For Res 22: 1044-1049.

Bradshaw HD, Otto K, Frewen B, McKay J, Schemske D (1998). Quantitative trait loci affecting differences in floral morphology between two species of monkeyflower (Mimulus). Genetics 149: 367-382

Britvin E, Minkov D, Glikson L, Ronin Y, Korol A (2001). MultiQtl, an interactive package for genetic mapping of correlated quantitative trait complexes in multiple environments, version 2.0 (Demo). Plant E Animal Genome IX. San Diego, CA. abstract C01_01.html.

Brondani C, Rangel PHN, Brondani RPV, Ferreira ME (2002). QTL mapping and introgression of yield-related traits from Oryza glumaepatula to cultivated rice (Oryza sativa) using microsatellites markers. Theor Appl Genet 104: 1192-1203.

Cervera MT, Remington D, Frigerio JM, Storme V, Ivens B, Boerjan W, Plomion C (2000). Improved AFLP analysis of tree species. Can J For Res 30: 1608-1616.

Churchill GA, Doerge RW (1994). Empirical threshold values for quantitative trait mapping. Genetics 138: 963-971.

Dupouey JL (1983). Analyse multivariable de quelques caractères morphologiques de populations de chênes (Quercus petraea (Matt.) Liebl. et Quercus robur L.) du Hurepoix. Ann Sci For 40: 187-194.

Dupouey JL, Badeau V (1993). Morphological variability of oaks (Quercus robur L, Quercus petraea (Matt) Liebl, Quercus pubescens Willd.) in northeastern France: preliminary results. Ann Sci For 50(Suppl. 1): 35s-40s.

Gömöry DA (2000). Gene coding for a non-specific NADdependent dehydrogenase shows a strong differentiation between Quercus robur and Quercus petraea. For Genet 7: 167-170.

Grandillo S, Tanksley SD (1996). QTL analysis of horticultural traits differentiating the cultivated tomato from the closely related species Lycopersicon pimpinellifolium. Theor Appl Genet 92: 935-951.

Grattapaglia D, Sederoff R (1994). Genetic linkage maps of Eucalyptus grandis and E. urophylla using a pseudo-testcross mapping strategy and RAPD markers. Genetics 137: 1121-1137.

Jansen RC, Stam P (1994). High resolution of quantitative traits into multiple loci via interval mapping. Genetics 136 1447-1455.

Jiang C, Wright R, Woo S, DelMonte T, Paterson A (2000). QTL analysis of leaf morphology in tetraploid Gossypium (cotton). Theor Appl Genet 100: 409-418.

Kampfer S, Lexer C, Glössl J, Steinkellner H (1998). Characterization of (GA)n microsatellite loci from Quercus robur. Hereditas 129: 183-186.

Kim SC, Rieseberg L (1999). Genetic architecture of species differences in annual sunflowers: implications for adaptive trait introgression. Genetics 153: 965-977.

Kissling P (1980). Clé de détermination des chênes médioeuropéens (Quercus L.). Ber schweiz bot Ges 90: 1-28.

Kleinschmit J, Kleinschmit JGR (2000). Quercus robur-Quercus petraea: a critical review of the species concept. Glasn $\mathrm{Za}$ Sumske Pokuse 37: 441-452.

Kosambi DD (1944). The estimation of map distance from recombination values. Ann Eugen 12: 172-175.

Kremer A, Dupouey JL, Deans JD, Cottrell J, Csaikl U, Finkeldey R, Espinel S, Jensen J, Kleinschmit J, Van Dam B, Ducousso A, Forrest I, de Heredia UL, Lowe A, Tutkova M, Munro RC, Steinhoff S, Badeau V (2002). Leaf morphological differentiation between Quercus robur and Quercus petraea is stable across western European mixed oak stands. Ann For Sci 59: 777-787.

Kremer A, Petit RJ (1993). Gene diversity in natural populations of oak species. Ann Sci For 50(Suppl. 1): 186s-202s.

Lan TH, Paterson AH (2001). Comparative mapping of QTLs determining the plant size of Brassica oleracea. Theor Appl Genet 103: 383-397.

Lander ES, Botstein D (1989). Mapping Mendelian factors underlying quantitative traits using RFLP linkage maps. Genetics 121: 185-199.

Lander ES, Green P, Abrahamson J, Barlow A, Daly MJ, Lincoln SE Newburg L (1987). MAPMAKER: an interactive computer package for constructing primary genetic linkage maps of experimental and natural populations. Genomics 1: 174-181.

Lin JZ, Ritland K (1997). Quantitative trait loci differentiating the outbreeding Mimulus guttatus from inbreeding $\mathrm{M}$. platycalyx. Genetics 146: 1115-1121.

Mariette S, Cottrell J, Csaikl UM, Goikoechea P, König A, Lowe AJ, Van Dam BC, Barreneche T, Bodénès C, Streiff R, Burg K, Groppe K, Munro RC, Tabbener H, Kremer A (2002). Comparison of levels of genetic diversity detected with AFLP and microsatellite markers within and among mixed Q. petraea (Matt.) Liebl. and Q. robur L. stands. Silvae Genet $\mathbf{5 1}$ 72-79.

Mayr E (1963). Populations, espèces et évolutions. Ed Hermann: Paris.

Moreau F, Kleinschmit J, Kremer A (1994). Molecular differentiation between $Q$. petraea and $Q$. robur assessed by random amplified DNA fragments. For Genet 1: 51-64.

Figure 2 Distribution of QTLs for the most discriminant leaf morphology traits ( $P<5 \%$ at the chromosome level): petiole length (PL), number of intercalary veins (NV), sinus width (SW), pubescence in the central part of the lamina (PUl), pubescence along the vein (PUv), basal shape lamina (BS). Index 1 corresponds to QTLs detected in experiment 1, index 2 corresponds to QTLs detected in experiment 2. Each QTL is delineated by the position of the highest LOD score and the bootstrap mean value of the highest LOD score. Confidence intervals of their position based on 1000 bootstrap samples are indicated as lines. 
Muir G, Fleming CC, Schlötterer C (2001). Three divergent rDNA clusters predate the species divergence in Quercus petraea (Matt.) Liebl. and Quercus robur L. Mol Biol Evol 18: $112-119$.

Olsson U (1975). A morphological analysis of phenotype in populations of Quercus (Fagaceae) in Sweden. Bot Notiser 128: $55-68$.

Orr A (2001). The genetics of species differences. Trends Ecol Evol 16: 343-350.

Petit RJ, Kremer A (1993). Ribosomal DNA and chloroplast DNA polymorphisms in a mixed stand of Quercus robur and $Q$ petraea. Ann Sci For 50(Suppl. 1): 41s-47s.

Poncet V, Martel E, Allouis S, Devos KM, Lamy F, Sarr A, Roberts T (2002). Comparative analysis of QTL affecting domestication traits between two domesticated $\times$ wild pearl millet (Pennisetum glaucum L. Poaceae) crosses. Theor Appl Genet 104: 965-975.

Rushton BS (1977). Artificial hybridization between Quercus robur L. and Quercus petraea (Matt.) Liebl. Watsonia 11: 229-236.

Rushton BS (1979). Quercus robur L. and Quercus petraea (Matt.) Liebl.: a multivariate approach to the hybrid problem, 2 . The geographical distribution of population types. Watsonia 12: 209-224.

Steinkellner H, Fluch S, Turetschek E, Lexer C, Streiff R, Kremer A, Burg K, Glossl J (1997). Identification and characterization of (GA/CT) $n_{n}$-microsatellite loci from Quercus petraea. Plant Mol Biol 33: 1093-1096.
Visscher PM, Thompson R, Haley CS (1996). Confidence intervals in QTL mapping by bootstrapping. Genetics 143: 1013-1020.

Voorrips RE (2001). MapChart version 2.0: Windows Software for the Graphical Presentation of Linkage Maps and QTLs. Plant Research International, Wageningen: The Netherlands.

Vos P, Hogers R, Bleeker M, Rijans M, Van de Lee T, Hornes M et al (1995). AFLP: A new technique for DNA fingerprinting. Nucleic Acids Res 23: 4407-4414.

Westerbergh A, Doebley J (2002). Morphological traits defining species differences in wild relatives of maize are controlled by multiple quantitative trait loci. Evolution 56: 273-283.

Wilcox P, Richardson T, Carson S (1997). Nature of quantitative trait variation in Pinus radiata: insights from QTL detection experiments. Proceeding of IUFRO. NZ, 1-4 December, pp 304-312.

Zanetto A, Roussel G, Kremer A (1994). Geographic variation of inter-specific differentiation between Quercus robur L. and Quercus petraea (Matt.) Liebl. For Genet 1: 111-123.

Zeng ZB (1994). Precise mapping of quantitative trait loci. Genetics 136: 1457-1468.

Zeng ZB, Liu JJ, Stam LF, Kao CH, Mercer, JM, Laurie CC (2000). Genetic architecture of a morphological shape difference between two Drosophila species. Genetics 154: 299-310.

Zoldos V, Siljak-Yakovlev S, Papes D, Sarr A, Panaud O (2001). Representational difference analysis reveals genomic differences between $Q$. robur and $Q$. suber: implications for the study of genome evolution in the genus Quercus. Mol Genet Genom 265: 234-241. 